\title{
PIC Based Protection of Single Phase Induction Motor
}

\author{
Lata Chavan ${ }^{1}$, Prerana Chafekar ${ }^{2}$, Avnish Bhatt ${ }^{3}$, Mitesh Patel ${ }^{4}$, Sarika Kuhikar $^{5}$ \\ U.G. Student, Department of Electronics Engineering, V.E.S.I.T, Mumbai, India ${ }^{1,2,3,4}$ \\ Assistant Professor, Department of Electronics Engineering, V.E.S.I.T, Mumbai, India ${ }^{5}$
}

\begin{abstract}
One of the most common electrical motor used in most applications is induction motor; hence analysis of induction motor is much essential to find out utilization index of a motor for better performance. Hence protecting induction motor from some faults is necessary. The use of microcontroller technology has enabled the design of energy-efficient and cost-effective control systems for induction motors ${ }^{[3]}$. This paper presents PIC microcontroller based control system for protection of a single phase induction motor. Due to electrical fault the winding of motor get heated which leads to insulation failure and thus reduce the life time of motor. This protection scheme protects the single phase induction motor from under voltage, over voltage, over current and over heat ${ }^{[4]}$. It also measures speed of the motor. PIC microcontroller monitors the overall process.
\end{abstract}

Keywords: Induction Motor, PIC Microcontroller, Under Voltage, Over Voltage, Over Current, Over Heat, Speed.

\section{INTRODUCTION}

The single phase induction motor used for domestic purpose, commercial purpose and to some extent in industrial purpose. These motors are simple in construction, cheap in cost, reliable and easy to repair and maintain. Due to all these advantages the single phase motor finds its application in vacuum cleaner, fans, centrifugal pump, blowers, washing machine, small toys etc. but the possibility of fault is unavoidable and hence protection of single phase induction motor is needed otherwise a failure of motor can result in shut down of a generating unit or production line. Whatever be the outcomes of failure, such constitutions are undesirable since they constitute a decrease in overall system reliability and additional demands on manpower, finance and time in order to rectify the problems. In this task, the technique utilized is PIC microcontroller based protection system. The circuit will protect the motor from several faults such as under voltage, over voltage, overheating ${ }^{[4]}$.

The circuit is completely controlled by the PIC and Microcontroller and it will consistently monitor the voltage of the mains supply and if voltage goes abnormal it will switch off the motor. With the help of current transformer which senses the current and if it exceeds rated value then PIC sends signal to relay to break the circuit and switch off the motor. Protective functions of an induction motor are mainly intended to prevent over heating of its windings. Due to electrical faults there is increasing in overheating of the windings. So the LM35 senses the temperature and if it exceeds specified limit, the PIC will send signal to relay to switch off the motor. All parameters are displayed on LCD. This thesis describes a method to detect and protect faults in a single phase induction motor. Conventional current and voltage transformers, LM 35 and IR sensors are used to sense motor parameters continuously. The method is very sensitive, fast and detects faults while running the motor.

\section{THE SYSTEM STRUCTURE}

The complete block diagram of the proposed motor protection system is shown in Figure1. It consist of different sections like PIC controller for controlling complete system, voltage and current transformer for sensing voltage and current from mains, temperature sensor, IR sensor for speed measurement, LCD module and relay.

\section{CONTROLLER UNIT}

PIC controller is a main block in complete protection system. It controls overall operation of circuit. It sends signal to the relay for (over voltage) protection of motor. In over voltage protection of single phase induction motor protects the motor from the over voltage. When supply system has high voltage than the rated voltage of induction motor then over voltage protection circuit gets activated to protect the motor. Same concept is applied for under voltage.

When there is increase in load on the motor beyond the rated value then the overload condition occurs. Due to this increase in current beyond the rated value then motor gets heated up and causes harm to the motor. To overcome this situation, the over current sensing circuit is designed. 


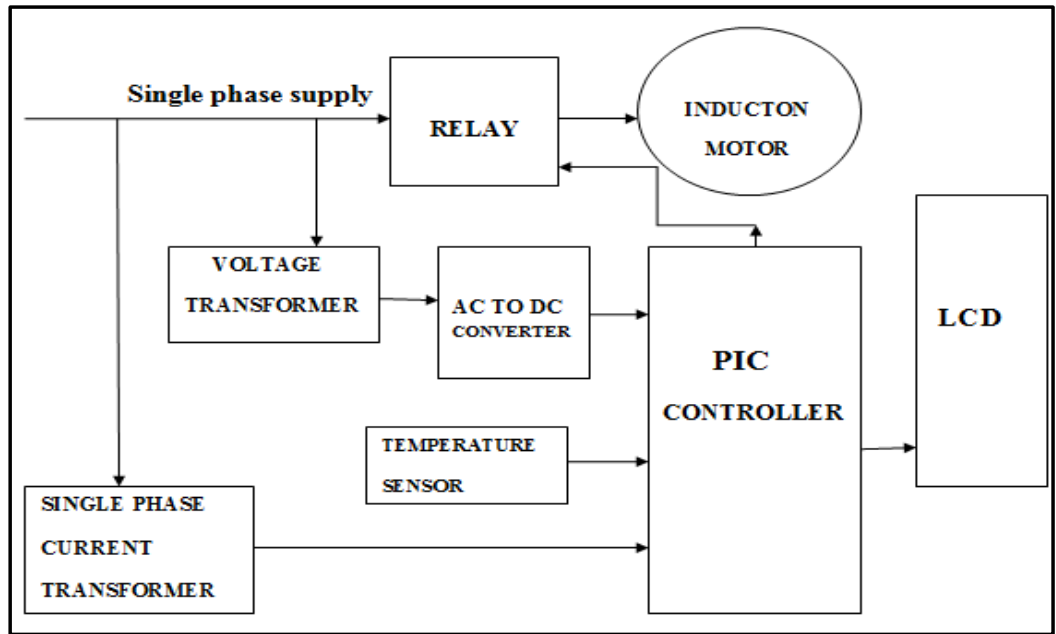

Figure 1: Main Block Diagram

\section{VOLTAGE AND CURRENT TRANSFORMER}

This section is works with the help of current transformer which is used to sense the current continuously.

\section{TEMPERATURE SENSOR}

When the motor works for longer time under loaded condition, it gets heated up which reduces efficiency of the motor. In this block, LM35 is used to sense temperature of the motor winding and output of LM 35 is directly fed to the PIC controller. If temperature crosses its rated value motor turns off. Speed is one of the important parameter of an induction motor.

\section{IR SENSOR}

Increase in speed beyond rated value can cause problems like poor performance, increase in operating temperature, which leads to reduce life of motor. IR sensor module is used to measure the speed.

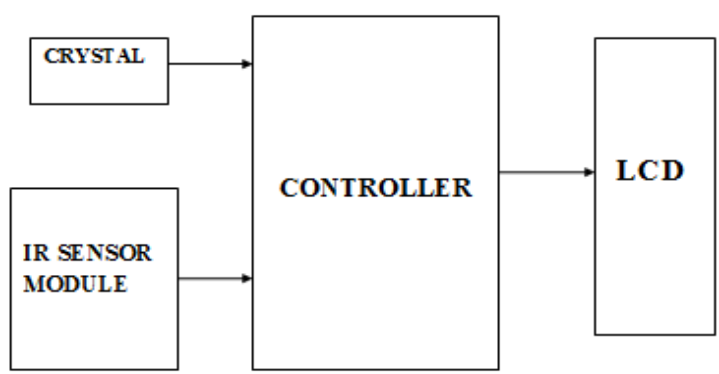

Figure 2: RPM Measurement Block

\section{DISPLAY MODULE}

Output from IR Sensor to the control system displays on LCD. It is used to display values of different parameters of induction motor like voltage, current, temperature and speed.

\section{RELAY}

Relay is connected to one of the pin of PIC and used to break the circuit at the occurrence of faults in motor to protect.

\section{HARDWARE DESIGN}

This system of protection of single phase induction motor can be implemented using PIC18F4520, current transformer, potential transformer, temperature sensor LM35, relay. Circuit gets activated when it gets the supply voltage. Motor will continue running until critical condition occurs. Voltage supply to the PIC is provided through transformer, diode rectifier and 7805 voltage regulator. Current transformer with rating of $5 \mathrm{Amp}$ provides current equivalent to supply current to pin number 2 of PIC, voltage transformer will provide supply voltage equivalent with maximum value of $12 \mathrm{~V}$ and LM35 will provide current temperature of motor to pin number 3 of controller. Whenever the measured voltage, current or temperature exceed the set value then controller will send signal to relay to turn off motor. Another module is used to measure the speed of the motor. It consists of controller 89S52, obstaclesensor and Display.IR 
module will work as an obstacle sensor, it will give a pulse signal when it detects the reflecting strip attached to the shaft of the motor. Controller is programmed to count the number of pulses received from the sensing module in one minute and to give speed of the motor in RPM (Rotation per Minute).

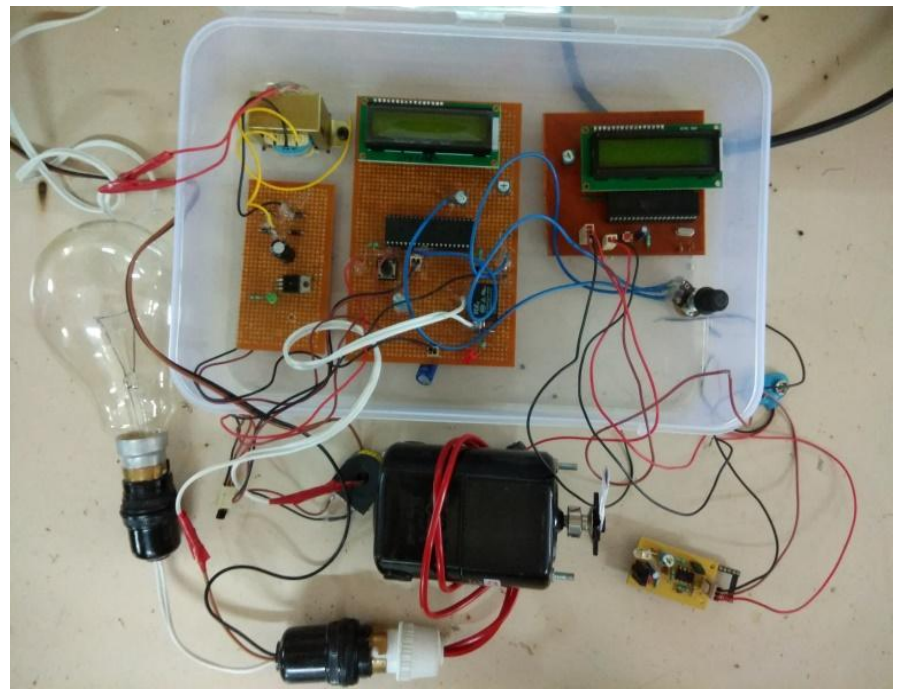

\section{FLOW CHART}

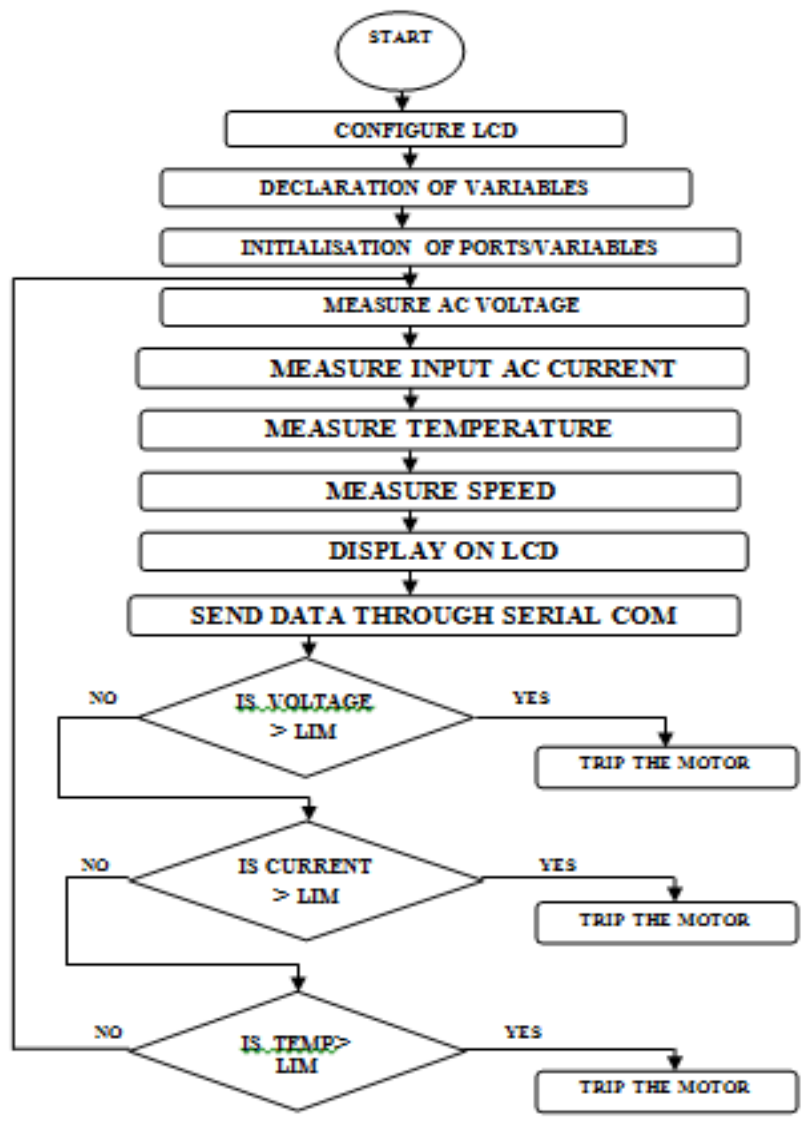

The flow chart gives complete overview of the project. It gives whole idea that how is it going to work.

\section{SOFTWARE REQUIREMENTS}

- The software tool that was used is C Basic Compiler

- Language:- C 


\section{RESULTS}

\section{UNDER VOLTAGE}

If supply voltage of motor is less than the specified limit then fault under voltage is detected and motor stop running.

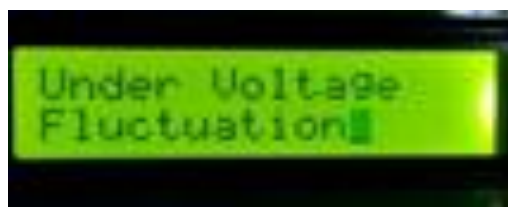

\section{OVER VOLTAGE}

If supply voltage is more than the specified limit then fault over voltage is detected and motor turns off.

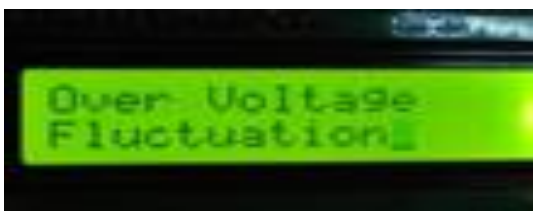

\section{OVER TEMPERATURE/ HEAT}

If temperature of motor crosses specified value then fault over heat is detected and relay break the circuit.

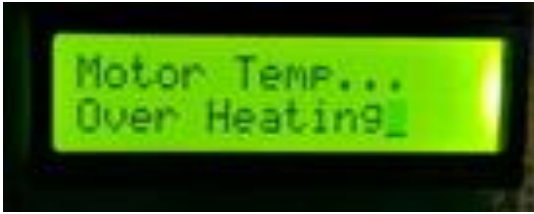

\section{SPEED MEASUREMENT}

Speed of the motor is measured using IR sensor and display on LCD.

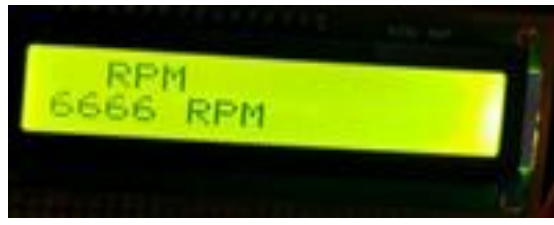

\section{ALL MEASUREMENTS}

Parameters of motor are displayed on LCD.

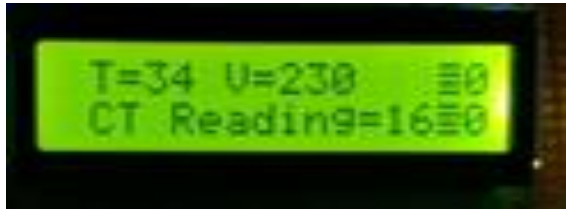

\section{CONCLUSION}

This system will protect the motor from several faults such as over voltage, over current, temperature and the circuit will switch on the motor under safety conditions. It also measures speed of the induction motor very accurately. It enhances the motor performance and make it reliable and increases its life.

\section{REFERENCE}

1. Shwetahugar, BasavarajAmarapur, 'Protection of Induction Motor using Microcontroller',Volume 6, Issue 5, May 2016

2. Rajasekar Thota, N. Shreerami Reddy, Roop Teja Neelurum, ' Microcontroller Based Protection and Control of a Low Voltage Motors by Using Zigbee Technology', vol. 04 special issue 01, 2013

3. Sayed M. Tag Eldin, Nivin Ghamry, 'A Pic Microcontroller-Based Protection of Three Phase Induction Motor, 2016

4. Prof. Ms. Madhuri Balasaheb Zambre,Mr. Vivek Vitthal Waiphale, Ms. Bhupali Popat Kumbar,'Microcontroller Based protection and Control of Three Phase Induction Motor', Volume 3, Issue 11 